Annals of International Medical and Dental Research

E-ISSN: 2395-2822 | P-ISSN: 2395-2814

Vol-8, Issue-2 | March-April 2022

DOI: 10.53339/aimdr.2022.8.2.7

Page no- 34-42 | Section- Research Article (Radiodiagnosis)

\title{
Non Traumatic and Non Hypertensive Intracerebral Bleed: Causes and Imaging Evaluation
}

\author{
Renu Yadav ${ }^{*}$, Meenu Amar², Prateek Madaan ${ }^{3}$
}

\begin{abstract}
${ }^{1}$ Department of Radiodiagnosis, VMMC \&SJH, New Delhi. India. Email id- doc.renu0803@gmail.com orchid id-0000-0003-4559-0596

2Department Of Radiodiagnosis, VMMC \& Safdarjung Hospital. New Delhi. India.

Email Id: meenu18789@gmail.com Orcid Id-0000-0002-0748-93

3Department of Radiodiagnosis, VMMC \& Safdarjung Hospital, New Delhi, India.

Email ID: madaan1991@gmail.com Orcid Id: 0000-0001-9363-6689
\end{abstract}

*Corresponding author

Received: 12 November 2021

Revised: 19 December 2021

Accepted: 31 December 2021

Published: 18 February 2022

\begin{abstract}
Background: Cross-sectional observational study was done in patients with nontraumatic, non-hypertensive intracerebral bleed undergoing cerebral angiography to study its different causes. Material \& Methods: Patients with all age groups presenting to the emergency with acute non-traumatic intra-cerebral bleed undergoing cerebral angiography in our institution for a time period of 6 months with a total of 200 patients were included in the study. Data collected were analyzed with respect to causes, distribution of aneurysms. Suspected cases of hypertensive bleed were excluded from the study population. Results: Noncontrast computed tomographic images showed positive findings in the form of either intra-axial/extra-axial bleed or infarct in 95\% of patients. However angiographic findings were positive in $52 \%$ of patients. Aneurysms were the most common positive angiographic findings ( $43 \%$ cases) with $95 \%$ of aneurysms were located in the circle of Willis. Majority of patients had solitary aneurysm while 6\% had multiple aneurysms. Conclusions: Among all non-traumatic, nonhpertensive intracerebral bleed aneurysms accounts for majority of the causes. Other causes include intraparenchymal arterio-venous malformations, cerebral venous thrombosis with hemorrhagic infarct and dural arteriovenous malformations (AVM).
\end{abstract}

Keywords:- Intracerebral bleed, Aneurysms, cerebral angiography.

\section{INTRODUCTION}

Intracranial hemorrhage $(\mathrm{ICH})$ has significant prognostic implication and can be categorized on the basis of etiology or anatomy. Common causes of spontaneous hemorrhage include hypertension, amyloid angiopathy, aneurysms and various vascular malformations, hemorrhagic transformation of ischaemic infarct, vasculitis, hemorrhagic metastasis.[1] Hypertensive bleed presents in old age, typically centered in gangliothalamic region, pons, cerebellum and occipital lobe.[1] Cerebral aneurysms are focal outpouchings from weakened areas of arterial wall.[2] Majority are located in circle of Willis and bleed into basal cisterns. Aneurysms are second most common cause of a subarachnoid hemorrhage, after trauma. [3] Arterio-venous malformations (AVMs) are abnormal arterio-venous connections with or without presence of intervening capillary bed.44] AVM are common cause of intraparenchymal bleed in young patient. Haemorrhagic transformation of ischaemic infarct typically seen during the subacute phase with initial imaging findings suggestive of an ischemic stroke. Dural venous 
Annals of International Medical and Dental Research E-ISSN: 2395-2822 | P-ISSN: 2395-2814

Vol-8, Issue-2 | March-April 2022

DOI: 10.53339/aimdr.2022.8.2.7

Page no- 34-42 | Section- Research Article (Radiodiagnosis)

sinus thrombosis commonly seen secondary to skull base infections, dehydration, hypercoagulable states and compression from meningioma or other dural tumors.[5] $\mathrm{ICH}$ secondary to venous sinus thrombosis does not follow an arterial territorial distribution and is centered over grey-white matter junction than cortex. $[6]$

Imaging assessment is done for detection of the bleeding, its classification on the basis of size and location, and exclusion of an underlying cause. It guides to further management.

Imaging modalities available for assessment are -

CT and CT Angiography- Most suitable for emergency assessment. Accurately diagnose location and severity of bleed. CT Angiography can detect most of the intracranial aneurysm larger than $3 \mathrm{~mm}$, along with that allows evaluation of osseous anatomy in relation to vessels for pre-operative planning. [7]

Magnetic Resonance Imaging and MR Angiography - Appearance of hematoma on MRI depends on its age. MRI has high diagnostic rate for detection of secondary causes, and can differentiate hemorrhagic transformation from primary bleed.[] Noncontrast MRA Time of Flight (TOF) provides good spatial resolution is most widely accepted technique, however it is sensitive to motion artifact and intrinsic T1 bright lesions produce transmitted signal on TOF images. Contrast MRA produces images with resolution similar to CTA. $[9,10]$

Digital Subtraction Angiography -DSA like CTA requires contrast administration plus inherent risk of arterial puncture. Effective performance of DSA requires obtaining adequate planer projection to permit the most precise possible aneurysm measurements.

Current study aims to evaluate different causes of non-traumatic non-hypertensive intracerebral bleed presenting in emergency department undergoing angiography study.

\section{MATERIAL AND METHODS}

It was cross-sectional observational study was done in our institution for a time period of 6 months with total of 200 patients were included.

Patients with all age groups presented with acute non-traumatic intra-cerebral bleed undergoing CT angiography were included in the study after written informed consent. Patient with suspected hypertensive bleed were excluded from the study.

Collected data was analyzed with respect to non contrast Computed Tomography findings as site of bleed, or maximum amount of clot with possible clue to cause of bleed.

CT Angiography images were evaluated on axial base images, and reconstructions like Multiplanar reconstruction (MPR), Maximum intensity projection (MIP), Surface shaded display (SSD). Data regarding aneurysm morphology, size, neck-artery ratio, neck-dome ratio were collected were analyzed.

\section{RESULTS}

\section{Demographic profile}

The study includes $67 \%$ (134) of males and 33\% (66) of females. Intracerebral bleed is 
Annals of International Medical and Dental Research E-ISSN: 2395-2822 | P-ISSN: 2395-2814

Vol-8, Issue-2 | March-April 2022

DOI: 10.53339/aimdr.2022.8.2.7

Page no- 34-42 | Section- Research Article (Radiodiagnosis)

uncommon in $<25$ years old population. Most common age group affected was middle aged (36-45years) involving one third of the patients with more than one fourth in the elderly age group (>55years).

\section{Type of bleed}

Almost half of the patients had intraparenchymal bleed with SAH followed by cisterns SAH and IVH in around one third of patients as listed in [Table 2].

All patients with isolated cisterns bleed shows circle of Willis aneurysm, while 29\% patients with intra-parenchymal bleed with surrounding SAH show aneurysm on angiographic studies.

\section{Angiographic findings}

Around half of the patient population had normal angiographic findings. Aneurysms were the most common cause of non traumatic / non hypertensive bleed as listed in [Table 3].

\section{Anatomical distribution of aneurysms}

One third of the patients had involvement of territory of middle cerebral artery (MCA) followed by Anterior communicating artery (ACoM) involvement in one fourth of the patient population as shown in [Table 4].

Table 1: Showing age wise distribution of study population.

\begin{tabular}{|l|l|}
\hline Age( in years) & \% Population \\
\hline$<25$ & $5 \%$ \\
\hline $26-35$ & $20 \%$ \\
\hline $36-45$ & $33.3 \%$ \\
\hline $46-55$ & $12.8 \%$ \\
\hline$>55$ & $28.9 \%$ \\
\hline
\end{tabular}

Table 2: Non contrast computed tomography (NCCT) Head findings are as detailed below.

\begin{tabular}{|l|l|}
\hline NCCT Findings & \% Population \\
\hline Intraparenchymal bleed with SAH & 45 \\
\hline Cisterns SAH and IVH & 29 \\
\hline Basal ganglia bleed & 5 \\
\hline Watershed infarct & 5 \\
\hline Atrophic changes or gliotic areas & 16 \\
\hline
\end{tabular}

Table 3: Angiographic findings of patients included in the study.

\begin{tabular}{|l|l|}
\hline Causes & \% \\
\hline Aneurysms & $43.2 \%$ \\
\hline Arterio-venous malformation (AVM) & $2.6 \%$ \\
\hline Cerebral venous thrombosis (CVT) & $2.6 \%$ \\
\hline Tumor & $2.6 \%$ \\
\hline Normal & $48 \%$ \\
\hline
\end{tabular}


Annals of International Medical and Dental Research E-ISSN: 2395-2822 | P-ISSN: 2395-2814

Vol-8, Issue-2 | March-April 2022

DOI: 10.53339/aimdr.2022.8.2.7

Page no- 34-42 | Section- Research Article (Radiodiagnosis)
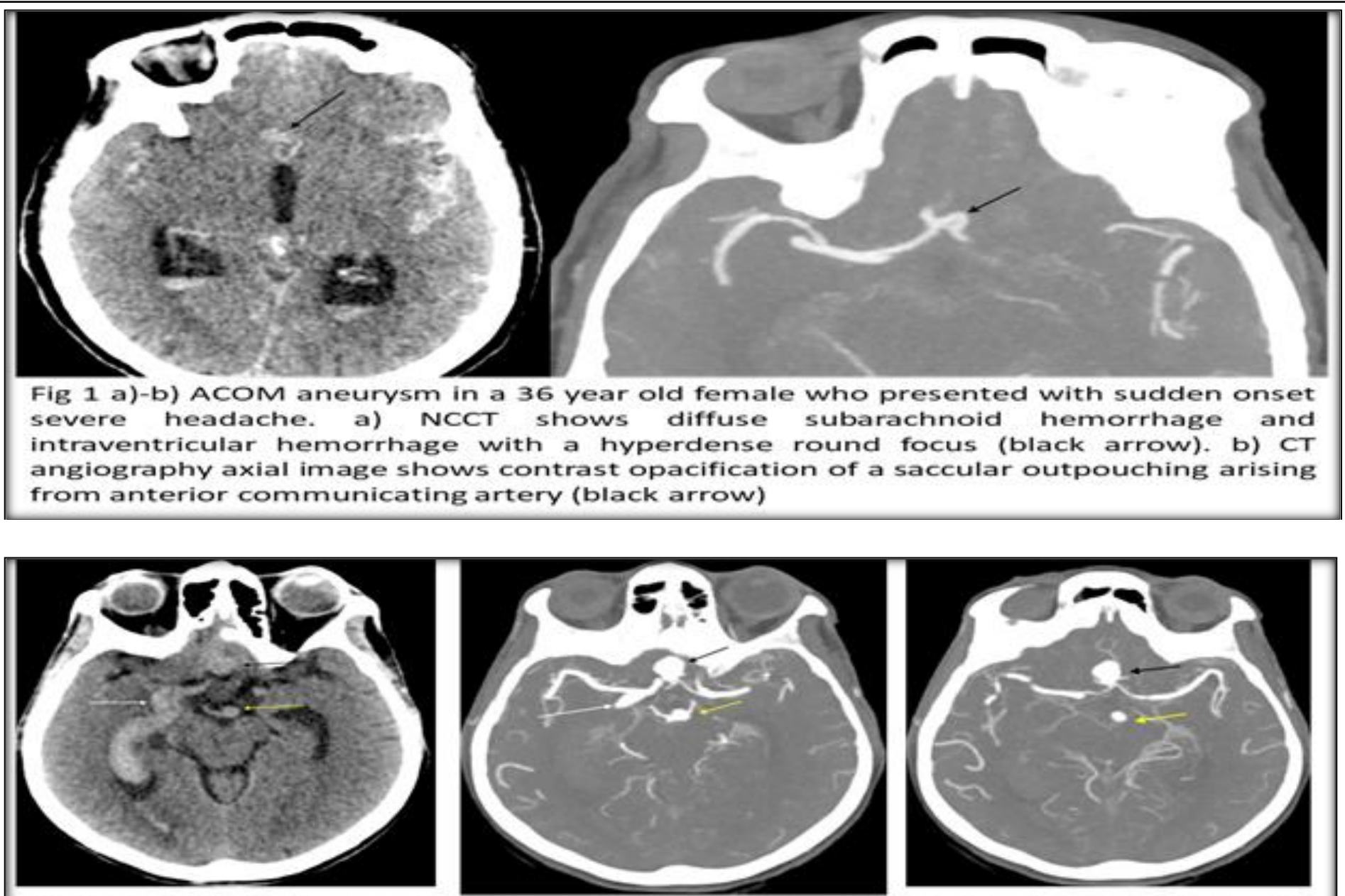

Fig 2 a)-c) Multiple saccular aneurysms in a 60 year old female who presented with seizures and raised intracranial pressure. a) NCCT scan showed intraventricular hemorrhage and subarachnoid hemorrhage(not shown). Multiple round hyperdense focii are seen in region of basal cistern. b) and c) shows axial CT angiographic images in same patient. The hyperdense focii in NCCT are visualised as contrast opacified saccular aneurysm arising from Anterior communicating artery (black arrow), right middle cerebral artery (white arrow) and top of basilar artery (yellow arrow).

Table 4: Anatomical distribution of aneurysms in the studied population.

\begin{tabular}{|l|l|}
\hline Location & \% \\
\hline Anterior communicating artery (ACoM) & 29 \\
\hline Internal carotid artery (ICA) & 10 \\
\hline Middle cerebral artery bifurcation (MCA) & 36 \\
\hline Basilar top aneurysm & 5 \\
\hline ACA - ACoM junction & 10 \\
\hline Anterior Cerebral Artery (ACA) & 5 \\
\hline Intraparenchymal (Mycotic) aneurysm & 5 \\
\hline
\end{tabular}


Annals of International Medical and Dental Research

E-ISSN: 2395-2822 | P-ISSN: 2395-2814

Vol-8, Issue-2 | March-April 2022

DOI: 10.53339/aimdr.2022.8.2.7

Page no- 34-42 | Section- Research Article (Radiodiagnosis)

Table 5: Size of aneurysm in the study population

\begin{tabular}{|l|l|}
\hline Size & \% \\
\hline$<5 \mathrm{~mm}$ & 53 \\
\hline $6-15 \mathrm{~mm}$ & 47 \\
\hline$>25 \mathrm{~mm}$ & - \\
\hline
\end{tabular}

[Figure 1] shows imaging findings in aneurismal bleed.

All patients with aneurysmal bleed had solitary aneurysm except three patients having multiple aneurysms. Most aneurysms were located in the circle of Willis. 5\% aneurysms had intraparenchymal location with mycotic origin.

[Figure 2] shows multiple aneurysms in circle of wilis.

\section{Size of aneurysm}

No aneurysm of more than $25 \mathrm{~mm}$ was detected, with half of them below $5 \mathrm{~mm}$ of size and other half in the range of $6-15 \mathrm{~mm}$ was noted as shown in [Table 5].

\section{DISCUSSION}

Intra-parenchymal bleed is a medical event with significant morbidity and mortality. Its causes can be divided into traumatic and nontraumatic. Non-traumatic causes could be hypertension, cerebral amyloid angiopathy, hemorrhagic conversion of ischemic infarction, cerebral aneurysms, cerebral arteriovenous malformations, dural arteriovenous fistula, vasculitis, and venous sinus thrombosis1. Hypertension and cerebral amyloid angiopathy comprises approx $85 \%$ of causes of non-traumatic intracerebral bleed.[11] Anatomically it can be described as intra-axial or extra-axial further into intraventricular, subarachnoid, subdural, or extradural. Spontaneous SAH is due to a ruptured arterial aneurysm in 70-80 per cent of patients, arteriovenous malformation in about 10 per cent while in the remaining 15 per cent, no underlying cause could be found on angiography.[12]

Neuroimaging provides proper diagnosis, guides further management and has prognostic significance. NCCT Head forms the cornerstone of imaging. CT angiography done to diagnose aneurysms, vascular malformation which comprises another significant causes of intracerebral bleed after ruling out two most common causes hypertension and cerebral amyloid angiopathy. MR and MRA characterize age of hematoma and diagnose vascular malformations with best diagnostic accuracy. Intra-arterial digital subtraction angiography is the gold standard, but being an invasive test it carries a risk of $1 \%$ \& $0.5 \%$ respectively for transient and permanent neurological complication.[13]

The annual rupture rate of small aneurysms $(<10 \mathrm{~mm})$ is very less in patient with no history of $\mathrm{SAH}$, however the risk increases 10 times with history of SAH. Aneurysms with a diameter of $10 \mathrm{~mm}$ or more are at critical risk for rupture. [14] Aneurysms encountered in our study were $<15 \mathrm{~mm}$ in size with $53 \%$ were $<5 \mathrm{~mm}$ and $47 \%$ were in the range of 6$15 \mathrm{~mm}$.Similar observation was made by Meyer et al.[15] 
Annals of International Medical and Dental Research

E-ISSN: 2395-2822 | P-ISSN: 2395-2814

Vol-8, Issue-2 | March-April 2022

DOI: 10.53339/aimdr.2022.8.2.7

Page no- 34-42 | Section- Research Article (Radiodiagnosis)

NCCT head revealed either intra/extra axial bleed in approximately $80 \%$ of studied population. While rest $20 \%$ showed either atrophic changes or watershed infarct.

Of all the angiographic studies done $48 \%$ were normal. Aneurysmal bleed comprises the $2^{\text {nd }}$ most common finding on angiography. CVT, AVMs and tumoral bleed each contribute approx $2.6 \%$ of causes. In patients having intraparenchymal bleed with normal angiography either proper history couldn't be illicited as intracerebral bleed was secondary to fall or because of bleed patient become unconscious and fall on ground, or cause remains elusive on CT angiography. Blood in subarachnoid spaces increases attenuation of CSF, which decreases with time elapsed, hence decreasing sensitivity with time.

Most aneurysms are located in the circle of Willis and therefore blood is maximally seen in the basal cisterns. Most common location is MCA bifurcation (36\%) while 2nd most common location is ACoM (29\%). Only 5\% has intraparenchymal location and mycotic in origin. While Brisman et al.[16] observed most common location is anterior communicating artery $(30-35 \%)$, the posterior communicating artery (30-35\%), followed by the middle cerebral artery bifurcation (20\%). In the UCAS cohort, MCA aneurysms (36.2\%) were twice as common as ICA $(18.6 \%)$, ACom $(15.5 \%)$ or
ICA/posterior communicating aneurysms.[17]

$(15.5 \%)$

Solitary saccular aneurysms are the most frequent form of aneurysms encountered in aneurismal bleed followed by multiple aneurysms. 18] Intracranial aneurysms found in our study also were saccular, solitary and occur at predictable location. Multiple aneurysms were encountered in $11 \%$ of the studied population.

Fusiform aneurysms develop from ectatic, tortuous cerebral arteries, mostly in the vertebrobasilar system. Dissecting aneurysms are the result of cystic medial necrosis or a traumatic tear of an artery. None of the unusual types like dissecting, fusiform, serpentine, blood blister type were encountered in our study.

Among other causes of spontaneous nonhypertensive intracranial bleed cerebral venous thrombosis and arteriovenous malformation account for $2.6 \%$ of the cases each. [Figure 3 and 4] show representative case of each.

The limitation of the present study is that it evaluates only symptomatic patients, true prevalence and distribution of intracranial aneurysms not assessed. Moreover, MRA and DSA was not done, patients were directly taken up for surgery. 
Annals of International Medical and Dental Research E-ISSN: 2395-2822 | P-ISSN: 2395-2814

Vol-8, Issue-2 | March-April 2022

DOI: 10.53339/aimdr.2022.8.2.7

Page no- 34-42 | Section- Research Article (Radiodiagnosis)

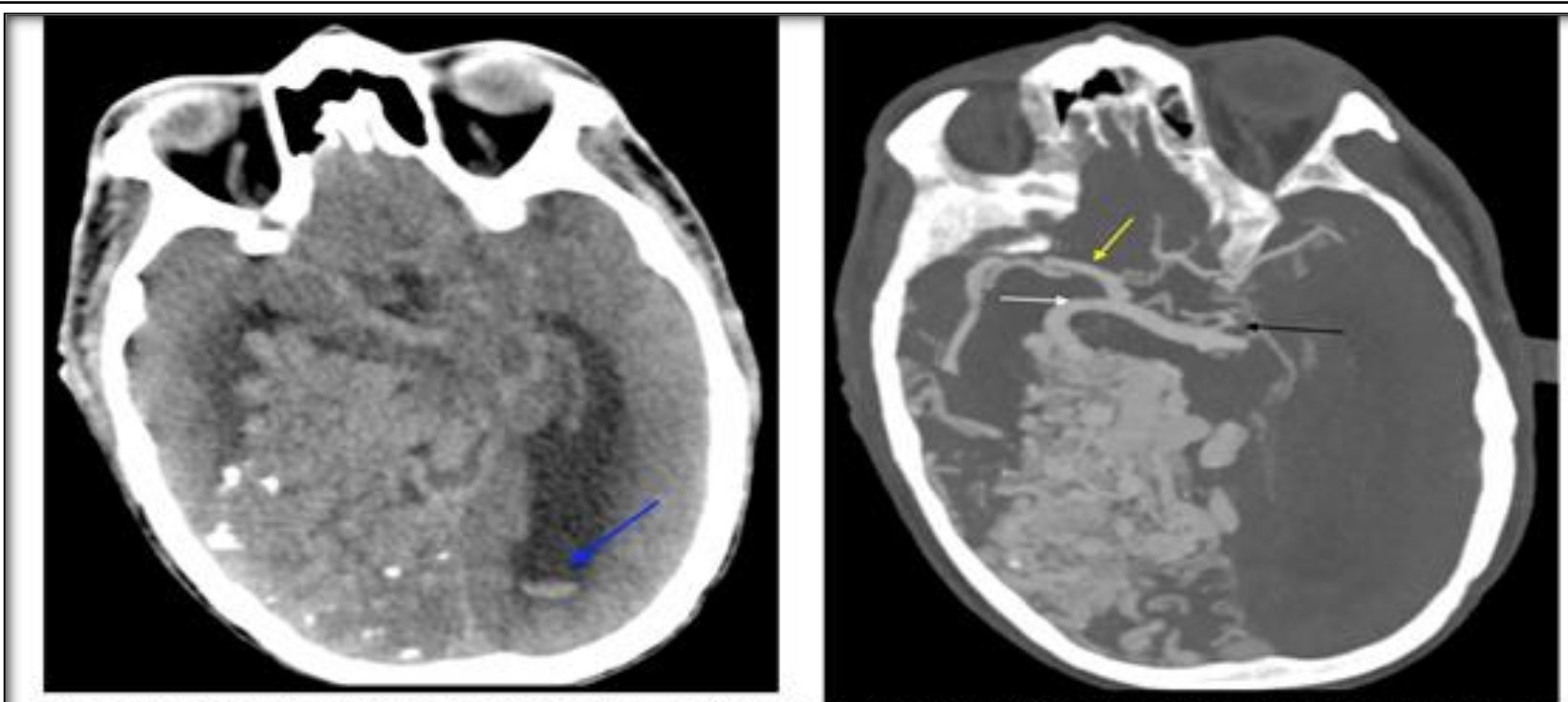

Fig 3 a)-b) Right cerebral hemispheric arteriovenous malformation in a 25 year old male who presented with seizures, a) NCCT head shows a large heterogeneously hyperdense lesion in right cerebral hemisphere with multiple small calcifications within and intraventricular hemorrhage in left lateral ventricle (blue arrow). Based on the appearance, a provisional diagnosis of vascular malformation was made. b) shows axial $C T$ angiography image performed in the same patient. There is a large intraparenchymal nidus with dilated ipsilateral posterior cerebral artery(white arrow in b) compared to attenuated left PCA (black arrow in b) and dilated ipsilatera MCA (yellow arrow in b).

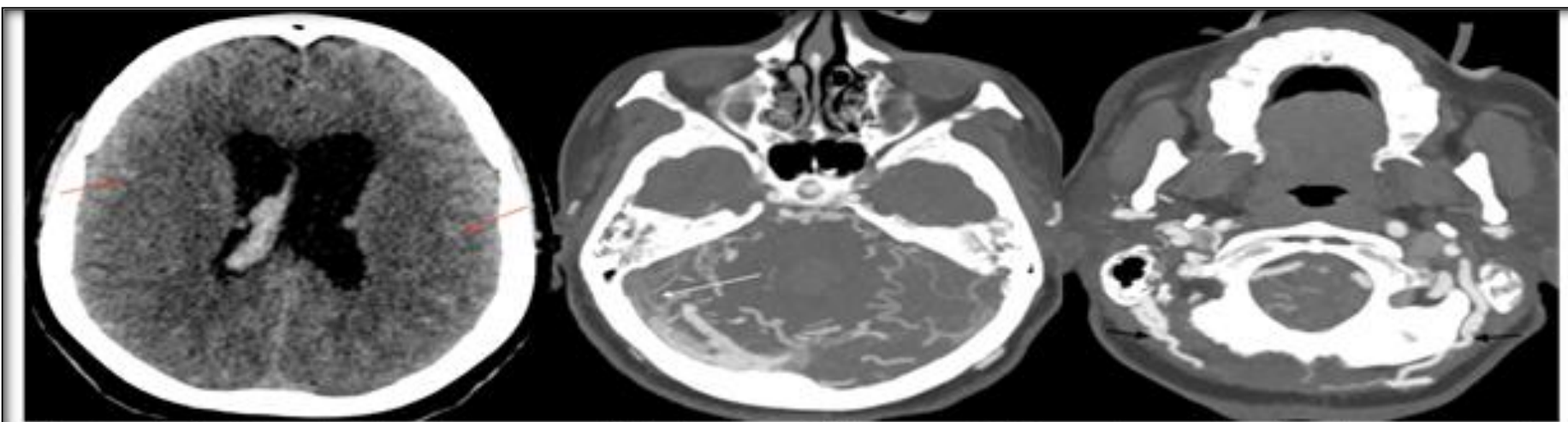

Fig 4 a)-c). Dural Arteriovenous fistula in a 35 year old female patient who presented with multiple seizure episodes for past 2 weeks. a) NCCT scan showed subarachnoid hemorrhage and intraventricular hemorrhage. Multiple hyperdense focii are seen within brain parenchyma (red arrows) which are not consistent with microbleeds. b) axial CT angiography image shows occluded distal right transverse sinus (white arrow). Multiple serpentine dilated channels (early venous filling) are seen bilaterally. No dilatation of ipsilateral major artery seen. Most of the dural venous sinuses showed early opacification. c) Axial image at a lower level shows dilated and toruous bilateral occipital arteries (black arrows). Based on the appearance, provisional diagnosis of Dural AVF was made.

Copyright: $\odot$ The author(s), published in Annals of International Medical and Dental Research, Vol-8, Issue-2. This is an open access article under the Attribution-Non Commercial 2.0 Generic (CC BY-NC 2.0) license. (https://creativecommons.org/licenses/by-nc/2.0/) 
Annals of International Medical and Dental Research E-ISSN: 2395-2822 | P-ISSN: 2395-2814

Vol-8, Issue-2 | March-April 2022

DOI: 10.53339/aimdr.2022.8.2.7

Page no- 34-42 | Section- Research Article (Radiodiagnosis)

\section{CONCLUSIONS}

Aneurysmal bleed is the most common etiology in the non-traumatic, nonhypertensive intracerebral bleed with MCA bifurcation being the most common site closely followed by anterior communicating artery. CT

\section{REFERENCES}

1. Heit JJ, Iv M, Wintermark M. Imaging of Intracranial Hemorrhage. J Stroke. 2017;19(1):11-27. doi: 10.5853/jos.2016.00563.

2. Kumar S, Goddeau RP Jr, Selim MH, et al. Atraumatic convexal subarachnoid hemorrhage: clinical presentation, imaging patterns, and etiologies. Neurology. 2010;74(11):893-899. doi:10.1212/WNL.0b013e3181d55efa

3. D'Souza S. Aneurysmal Subarachnoid Hemorrhage. J Neurosurg Anesthesiol. 2015;27(3):222-240. doi:10.1097/ANA.0000000000000130

4. Graves VB, Duff TA: Intracranial arteriovenous malformations: Current imaging and treatment. Invest Radiol . 1990;25:952-960. https://doi.org/10.1097/00004424-199008000-00014

5. Ferro JM, Canhão P. Acute treatment of cerebral venous and dural sinus thrombosis. Curr Treat Options Neurol. 2008;10(2):126-37. doi: 10.1007/s11940-008-0014-0.

6. Saposnik G, Barinagarrementeria F, Brown RD Jr, Bushnell CD, Cucchiara B, Cushman $M$, et al. American Heart Association Stroke Council and the Council on Epidemiology and Prevention. Diagnosis and management of cerebral venous thrombosis: a statement for healthcare professionals from the American Heart Association/American Stroke Association. Stroke. 2011;42(4):1158-92. doi: 10.1161/STR.0b013e31820a8364.

7. Teksam M, McKinney A, Casey S, Asis M, Kieffer S, Truwit CL. Multi-section CT angiography for detection of cerebral aneurysms. AJNR Am J Neuroradiol. 2004;25(9):1485-92.

8. Macellari F, Paciaroni M, Agnelli G, Caso V. Neuroimaging in intracerebral hemorrhage. Stroke. 2014;45(3):903-8.

doi: 10.1161/STROKEAHA.113.003701. and CTA forms the workhorse of imaging in emergency non-traumatic, non-hypertensive intracerebral bleed by providing diagnosis, etiology and guiding management strategy.

9. Nael K, Villablanca JP, Saleh R, Pope W, Nael A, Laub G, et al. Contrast-enhanced MR angiography at $3 \mathrm{~T}$ in the evaluation of intracranial aneurysms: a comparison with time-of-flight MR angiography. AJNR Am J Neuroradiol. 2006;27(10):2118-21.

10. Nael K, Villablanca JP, Mossaz L, Pope W, Juncosa A, Laub G, Finn JP. 3-T contrast-enhanced MR angiography in evaluation of suspected intracranial aneurysm: comparison with MDCT angiography. AJR Am J Roentgenol. 2008;190(2):389-95. doi: 10.2214/ AJR.07.2297.

11. Flower O, Smith M. The acute management of intracerebral hemorrhage. Curr Opin Crit Care. 2011;17(2):106-14. 10.1097/MCC.0b013e328342f823.

12. Atlas SW, Listerud J, Chung W, Flamm ES. Intracranial aneurysms: depiction on MR angiograms with a multifeature-extraction, raytracing postprocessing algorithm. Radiology. 1994;192(1):129-39. doi: 10.1148/radiology.192.1.8208924.

13. Mayberg MR, Batjer $H H$, Dacey $R$, Diringer $M$, Haley EC, Heros RC, et al. Guidelines for the management of aneurysmal subarachnoid hemorrhage. A statement for healthcare professionals from a special writing group of the Stroke Council, American Heart Association. Stroke. 1994;25(11):2315-28. doi: 10.1161/01.str.25.11.2315.

14. International Study of Unruptured Intracranial Aneurysms Investigators. Unruptured intracranial aneurysms--risk of rupture and risks of surgical intervention. N Engl J Med. 1998;339(24):1725-33. doi: 10.1056/NEJM199812103392401.

15. Meyers PM, Schumacher HC, Higashida RT, Derdeyn CP, Nesbit GM, Sacks D, et al; American Society of Interventional Neuroradiology; Society of Interventional Radiology. Reporting standards for endovascular repair of saccular intracranial cerebral 
Annals of International Medical and Dental Research

E-ISSN: 2395-2822 | P-ISSN: 2395-2814

Vol-8, Issue-2 | March-April 2022

DOI: 10.53339/aimdr.2022.8.2.7

Page no- 34-42 | Section- Research Article (Radiodiagnosis)

aneurysms. J Vasc Interv Radiol. 2009;20(7 Suppl):S435-50. doi: 10.1016/j.jvir.2009.03.004.

16. Brisman JL, Song JK, Newell DW. Cerebral aneurysms. N Engl J Med. 2006;355(9):928-39. doi: 10.1056/NEJMra052760.

17. UCAS Japan Investigators, Morita A, Kirino $\mathrm{T}$, Hashi K, Aoki N, Fukuhara S, et al. The natural course of unruptured cerebral aneurysms in a
Japanese cohort. N Engl J Med. 2012;366(26):2474-82. doi: 10.1056/NEJMoa1113260.

18. Keedy A. An overview of intracranial aneurysms. Mcgill J Med. 2006;9(2):141-146.

Source of Support: Nil, Conflict of Interest: None declared 